\title{
Challenges When Expanding Transcatheter Aortic Valve Implantation to Younger Patients
}

\author{
Ole De Backer* and Lars Søndergaard \\ The Heart Center, Rigshospitalet, Copenhagen, Denmark
}

The rapid expansion of transcatheter aortic valve implantation (TAVI) has been based upon robust clinical evidence derived from randomized controlled trials and large-scale international and national registries. Over the past decade, TAVI has evolved into a safe and effective procedure with predictable and reproducible outcomes. As a consequence, the TAVI technology is increasingly used to treat patients with a lower risk profile and the volume of TAVI now exceeds surgical aortic valve replacement (SAVR) in some countries. It may be anticipated that, in the near future, the majority of patients with severe symptomatic aortic valve stenosis will undergo TAVI as first line therapy, regardless of their age and risk profile. This article identifies some of the specific challenges that lie

OPEN ACCESS

Edited by:

Crochan John O'Sullivan, Triemli Hospital, Switzerland

Reviewed by: Andrew Roy,

Mater Private Hospital, Ireland,

Ireland

Ernest Spitzer,

Erasmus University Rotterdam,

Netherlands

Luigi Biasco,

Cardiocentro Ticino, Switzerland

${ }^{*}$ Correspondence:

Ole De Backer

ole.debacker@gmail.com

Specialty section:

This article was submitted to Structural Interventional Cardiology, a section of the journal

Frontiers in Cardiovascular Medicine

Received: 26 February 2018 Accepted: 24 April 2018

Published: 11 May 2018

Citation:

De Backer $O$ and Søndergaard $L$ (2018) Challenges When Expanding

Transcatheter Aortic Valve Implantation to Younger Patients.

Front. Cardiovasc. Med. 5:45. doi: 10.3389/fcvm.2018.00045 ahead when considering expansion of TAVI to younger patients.

Keywords: aortic valve stenosis, transcatheter aortic valve implantation, young adults, bicuspid aortic valve, challenges

Transcatheter aortic valve implantation (TAVI) has become an established therapeutic option for patients with symptomatic, severe aortic valve stenosis (AS) who are at increased risk for conventional cardiac surgery (1-4). In recent years, the TAVI technology is also increasingly used to treat patients with a lower risk profile - this practice is supported by results from the NOTION, PARTNER-II and SURTAVI trials indicating that TAVI is a viable option for patients with a low to intermediate surgical risk profile (5-7).

Although TAVI, in many countries, has become the default therapy to treat AS patients aged 75 years or more, there is currently increasing discussion on how far to push the limits when considering treating younger patients. Although the above-mentioned lower-risk TAVI trials included patients with a lower surgical risk score, the mean age of enrolled patients was not different compared to the early TAVI trials conducted in extreme or high risk patients (Figure 1) (1-7). When considering further expansion of TAVI indications to encompass younger patients aged 75 years or less, there are still some challenges ahead.

Based on currently available data, it can be stated that TAVI is non-inferior to surgery in terms of mortality and stroke, and is likely to be superior if a transfemoral approach is possible. Surgical patients more frequently experience major bleedings, acute kidney injury, and new-onset atrial fibrillation, whereas TAVI is associated with a higher rate of major vascular complications, paravalvular regurgitation, and pacemaker implantations (3-7). When considering expansion of TAVI to younger patients $<75$ years, it will be a must to obtain predictable and outstanding results, also for these latter procedural outcomes.

Over the past decade, the TAVI technology has matured; however, technological improvements have not come to a halt yet. New TAVI devices with lower-profile delivery systems have increased the proportion of patients who can be treated by transfemoral approach and have significantly reduced vascular complications (8). Newer generation TAVI devices also have an additional sealing skirt, which reduces the risk of paravalvular regurgitation, (9) and are often repositionable, which can result in higher implants thereby reducing the risk of conduction disorders (10). 


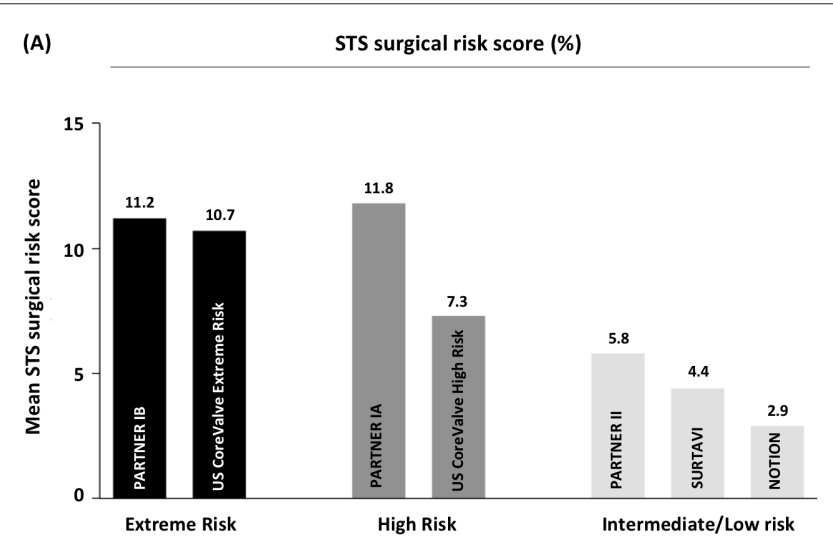

(B)

Age (years)

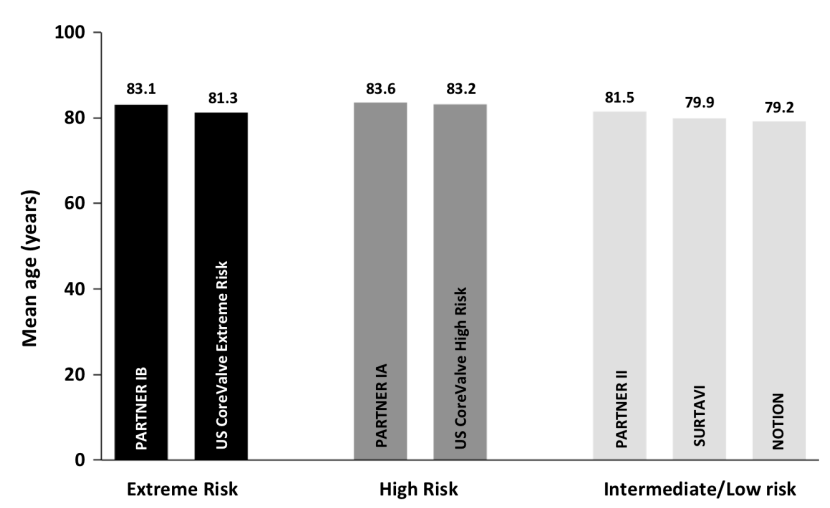

FIGURE 1 | Surgical risk and age profile in the different large randomized controlled TAVI trials, indicating the mean STS surgical risk score (in \%) and mean age (in years) for the TAVI group in every respective study. STS, Society of Thoracic Surgeons; TAVI, transcatheter aortic valve implantation.

Furthermore, procedural outcomes have improved because of increased operator experience and developments in cardiac and vascular imaging, particularly using multidetector CT.

As TAVI would move into younger AS populations, one pitfall may be that treating bicuspid valves would become an increasing part of practice - with an estimate of $30-50 \%$ in those patients aged 75 years or less (11). Importantly, patients with bicuspid AS have typically been excluded from the large randomized controlled trials. Today, only limited data exist on outcomes of TAVI in bicuspid AS. In a recent meta-analysis of 13 observational studies, short-term outcome data indicated that TAVI for bicuspid AS is associated with high device success rates and a good safety profile. Mortality at 30 days was low and comparable to that achieved with the newest generation TAVI devices in tricuspid AS. However, there was a trend towards higher rates of significant paravalvular regurgitation (12\%) and permanent pacemaker requirement (18\%) in bicuspid AS cohorts undergoing TAVI (12). An important issue when considering TAVI in bicuspid AS is the assessments of these patients' anatomy and the modification of the TAVI technique, with specific attention to valve deployment and positioning.
In order to overcome the limitations of the current generation TAVI devices with regards to paravalvular regurgitation and pacemaker requirement, the design of specific TAVI devices to treat bicuspid anatomy will become crucial.

Finally, extension of TAVI to younger patients with longer life-expectancy also raises the issue of durability. In 2016, some concern was raised about potential poor long-term durability of transcatheter heart valves - however, these results were based on less than 50 first generation valves and only echocardiographic findings were used to define valve degeneration (13) - which is in contrast with the "need for re-intervention" used as definition for surgical valve degeneration. Importantly, since then, robust 5 year follow-up data have come available demonstrating continued valve durability with low rates of hemodynamic valve dysfunction and/or re-intervention, and this for both balloon-expandable and self-expanding transcatheter heart valves $(1-3,14)$.

Recently, ESC, EAPCI and EACTS have published a consensus on standard definitions of structural valve deterioration (SVD) and bioprosthetic valve failure (BVF) in order to assess long-term durability of transcatheter and surgical aortic bioprosthesis (15). There should be clear distinction between SVD (the principal etiology) and BVF (the clinical correlate). SVD includes permanent (irreversible) intrinsic changes of the valve (i.e., leaflet tear, calcification, pannus deposition, flail, or fibrotic leaflet) leading to degeneration and/or dysfunction, which in turn may result in stenosis or intra-prosthetic regurgitation. The term BVF integrates severe SVD (i.e., the etiology) with its clinical consequences - thereby avoiding over-interpretation of valve-related outcomes in asymptomatic patients with no clinical impact - and is recommended to be used as the main outcome of interest in studies assessing the long-term performance of TAVI and SAVR. Importantly, BVF may occur in the setting of SVD but also as the consequence of pathophysiological processes unrelated to SVD, such as thrombosis, endocarditis or nonstructural valve dysfunction. BVF includes any of the following: (1) bioprosthetic valve dysfunction at autopsy, very likely related to the cause of death, or "valve- related death"; (2) aortic valve re-intervention (i.e., valve-in-valve TAVI, paravalvular leak closure or SAVR); and (3) severe hemodynamic SVD.

These definitions have been applied to the NOTION trial (7) - including $80 \%$ low risk patients - showing that, after five years, the rate of SVD was lower in transcatheter heart valves as compared to surgical aortic bioprosthesis (3.9\% vs. $26.1 \%$, respectively; $p<0.001)$, whereas the rate of BVF was similar in both groups ( $8.9 \%$ vs. $9.5 \%$, respectively; $p=0.89)$ - as presented at EuroPCR 2017.

As a large portion of the younger AS patients has a bicuspid valve, data on transcatheter heart valve durability and long-term outcomes in this specific cohort will also become essential. Given the anatomical characteristics of a stenotic bicuspid aortic valve, a concern may be that the implanted transcatheter heart valve may not fully expand or not become fully circular with asymmetric leaflets as a result. Although this should not necessarily lead to immediate valvular dysfunction, it has recently been reported that asymmetrical leaflet expansion may be associated with an increased risk of subclinical leaflet thrombosis (16). In 


\title{
Challenges when expanding TAVI to younger patients
}

\author{
- Need for predictable results, including rate of vascular complications, \\ paravalvular leakage, and new-onset permanent pacemaker.
}

- Higher prevalence of bicuspid aortic valve stenosis.

- Long-term valve durability.

FIGURE 2 | Summary figure: challenges when expanding transcatheter aortic valve implantation to younger patients.

addition, leaflet asymmetry may also have an impact on longterm valve durability. This is still important missing information when one considers treating a younger bicuspid AS patient with TAVI.

In conclusion, the rapid expansion of TAVI has been based upon robust clinical evidence derived from randomized controlled trials and large-scale international and national registries. Over the past decade, TAVI has evolved into a safe and effective procedure with predictable and reproducible outcomes. As a consequence, the volume of TAVI now exceeds SAVR in some countries (17). It may be anticipated that, in the near future, the majority of patients with severe symptomatic AS will undergo TAVI as first line therapy, regardless of their age and risk profile. This article identifies some of the specific challenges that lie ahead when considering expansion of TAVI to younger patients (Figure 2). With ongoing developments of the TAVI technology, it can be expected that most of these obstacles will be overcome within the next decade. Still, it will

\section{REFERENCES}

1. Kapadia SR, Leon MB, Makkar RR, Tuzcu EM, Svensson LG, Kodali S, et al. 5 -year outcomes of transcatheter aortic valve replacement compared with standard treatment for patients with inoperable aortic stenosis (PARTNER 1): a randomised controlled trial. Lancet (2015) 385(9986):2485-91. doi: 10.1016/ S0140-6736(15)60290-2

2. Popma JJ, Adams DH, Reardon MJ, Yakubov SJ, Kleiman NS, Heimansohn $\mathrm{D}$, et al. Transcatheter aortic valve replacement using a self-expanding bioprosthesis in patients with severe aortic stenosis at extreme risk for surgery. J Am Coll Cardiol (2014) 63(19):1972-81. doi: 10.1016/j. jacc.2014.02.556

3. . Mack MJ, Leon MB, Smith CR, Miller DC, Moses JW, Tuzcu EM, et al. 5-year outcomes of transcatheter aortic valve replacement or surgical aortic valve replacement for high surgical risk patients with aortic stenosis (PARTNER 1): a randomised controlled trial. Lancet (2015) 385(9986):2477-84. doi: 10.1016/ S0140-6736(15)60308-7

4. Reardon MJ, Adams DH, Kleiman NS, Yakubov SJ, Coselli JS, Deeb GM, et al. 2-Year outcomes in patients undergoing surgical or self-expanding transcatheter aortic valve replacement. J Am Coll Cardiol (2015) 66(2):113-21. doi: 10.1016/j.jacc.2015.05.017

5. Leon MB, Smith CR, Mack MJ, Makkar RR, Svensson LG, Kodali SK, et al. Transcatheter or surgical aortic-valve replacement in intermediate-risk patients. N Engl J Med (2016) 374(17):1609-20. doi: 10.1056/NEJMoa1514616 be essential to provide the necessary clinical evidence - within the framework of a randomized trial - comparing TAVI with SAVR. Although large TAVI trials have been initiated by Edwards Lifesciences (USA) and Medtronic (USA) in low-risk AS cohorts, this is not a guarantee that young patients will be enrolled. In additon, patients with bicuspid AS are excluded from these trials. Currently, the only large randomized controlled trial comparing TAVI with SAVR in low-risk, younger patients $\leq 75$ years of age, not excluding bicuspid valves, is the NOTION-2 trial (ClinTrials. Gov: NCT02825134). This randomized trial should provide the needed clinical evidence to evaluate the use of TAVI in young, low-risk AS patients.

\section{AUTHOR CONTRIBUTIONS}

ODB and LS both contributed to the concept, writing process and revision of this manuscript.

6. Reardon MJ, Van Mieghem NM, Popma JJ, Kleiman NS, Søndergaard L, Mumtaz M, et al. Surgical or transcatheter aortic-valve replacement in intermediate-risk patients. N Engl J Med (2017) 376(14):1321-31. doi: 10.1056/ NEJMoa1700456

7. Thyregod HG, Steinbrüchel DA, Ihlemann N, Nissen H, Kjeldsen BJ, Petursson $\mathrm{P}$, et al. Transcatheter versus surgical aortic valve replacement in patients with severe aortic valve stenosis: 1-year results from the all-comers NOTION randomized clinical trial. J Am Coll Cardiol (2015) 65(20):2184-94. doi: 10.1016/j.jacc.2015.03.014

8. Chaudhry MA, Sardar MR. Vascular complications of transcatheter aortic valve replacement: a concise literature review. World J Cardiol (2017) 9(7):57482. doi: $10.4330 /$ wjc.v9.i7.574

9. Arai T, Lefèvre T, Hovasse T, Morice MC, Garot P, Benamer H, et al. Comparison of Edwards SAPIEN 3 versus SAPIEN XT in transfemoral transcatheter aortic valve implantation: difference of valve selection in the real world. J Cardiol (2017) 69(3):565-9. doi: 10.1016/j.jjcc.2016.04.012

10. Auffret V, Puri R, Urena M, Chamandi C, Rodriguez-Gabella T, Philippon F, et al. Conduction disturbances after transcatheter aortic valve replacement: current status and future perspectives. Circulation (2017) 136(11):1049-69. doi: 10.1161/CIRCULATIONAHA.117.028352

11. Roberts WC, Ko JM, Jm K. Frequency by decades of unicuspid, bicuspid, and tricuspid aortic valves in adults having isolated aortic valve replacement for aortic stenosis, with or without associated aortic regurgitation. Circulation (2005) 111(7):920-5. doi: 10.1161/01.CIR.0000155623.48408.C5 
12. Reddy G, Wang Z, Nishimura RA, Greason KL, Yoon SH, Makkar RR, et al. Transcatheter aortic valve replacement for stenotic bicuspid aortic valves: systematic review and meta analyses of observational studies. Catheter Cardiovasc Interv (2018) 91(5):975-83. doi: 10.1002/ccd.27340

13. Dvir D. First look at long-term durability of transcatheter heart valves: assessment of valve function up to 10 years after implantation. EuroPCR May 17-20; Paris, France (2016).

14. Gerckens U, Tamburino C, Bleiziffer S, Bosmans J, Wenaweser P, Brecker S, et al. Final 5-year clinical and echocardiographic results for treatment of severe aortic stenosis with a self-expanding bioprosthesis from the ADVANCE Study. Eur Heart J (2017) 38(36):2729-38. doi: 10.1093/eurheartj/ehx295

15. Capodanno D, Petronio AS, Prendergast B, Eltchaninoff H, Vahanian A, Modine T, et al. Standardized definitions of structural deterioration and valve failure in assessing long-term durability of transcatheter and surgical aortic bioprosthetic valves: a consensus statement from the European Association of Percutaneous Cardiovascular Interventions (EAPCI) endorsed by the European Society of Cardiology (ESC) and the European Association for Cardio-Thoracic Surgery (EACTS). Eur J Cardiothorac Surg (2017) 52(3):40817. doi: $10.1093 /$ ejcts/ezx244
16. Fuchs A, de Backer O, Brooks M, de Knegt MC, Bieliauskas G, Yamamoto M, et al. Subclinical leaflet thickening and stent frame geometry in self-expanding transcatheter heart valves. EuroIntervention (2017) 13(9):e1067-75. doi: 10.4244/EIJ-D-17-00373

17. de Backer O, Luk NH, Olsen NT, Olsen PS, Søndergaard L. Choice of treatment for aortic valve stenosis in the era of transcatheter aortic valve replacement in Eastern Denmark (2005 to 2015). JACC Cardiovasc Interv (2016) 9(11):1152-8. doi: $10.1016 /$ j.jcin.2016.02.028

Conflicts of Interest Statement: The authors declare that the research was conducted in the absence of any commercial or financial relationships that could be construed as a potential conflict of interest.

Copyright $\odot 2018$ De Backer and Søndergaard. This is an open-access article distributed under the terms of the Creative Commons Attribution License (CC BY). The use, distribution or reproduction in other forums is permitted, provided the original author $(s)$ and the copyright owner are credited and that the original publication in this journal is cited, in accordance with accepted academic practice. No use, distribution or reproduction is permitted which does not comply with these terms. 